\title{
Observações sobre o pejorativo sufixal: testando a intuição dos falantes diante de uma teoria de fase nas palavras
}

\author{
Rafael Dias Minussi ${ }^{a}$ \\ Caroline da Silva Oliveirab*
}

\begin{abstract}
Resumo
Buscamos investigar as relações entre as propriedades semânticas e as propriedades sintáticas das formações de nomes pejorativos, refletindo sobre bases, afixos, produtos, e as relações estabelecidas entre eles Seguindo o modelo teórico da Morfologia Distribuída (Cf. HALLE; MARANTZ, 1993; MARANTZ, 1997), propomo-nos investigar e descrever a interface sintático-semântica (Cf. MINUSSI; NÓBREGA, 2014) na qual as formações pejorativas podem estar inseridas. Fundamentados em Frota (1985) e Sandmann (1989), por meio dos quais determinamos inicialmente quais sufixos seriam estudados, e, a teoria de fase nas palavras (MARANTZ, 2001; ARAD, 2003), selecionamos 306 palavras, em textos orais e escritos, coletados nas mais diversas mídias, tendo como conceito fundamental a intuição do falante. Realizamos testes para verificar a pejoratividade das bases, das formações resultantes e dos sufixos. A análise dos respectivos dados resultou na criação de uma escala de pejoratividade. Desse modo, entre os objetivos a serem alcançados no trabalho estão: a) contribuir para uma metodologia de investigação a respeito da pejoratividade, b) investigar a contribuição semântica do sufixo para a interpretação da pejoratividade, c) avançar no desenvolvimento dos estudos sobre a formação de palavras pejorativas e d) realizar uma análise da pejoratividade à luz da teoria de fase.
\end{abstract}

* Agradeço a FAPESP pela bolsa de IC concedida. Processo $\mathrm{n}^{\circ}$ Palavras-chave: Pejoratividade; Derivação sufixal; Sufixos avaliativos; Morfologia Distribuída; Teoria de fase.

Recebido em: 07/05/2018 Aceito em: 04/07/2018

\footnotetext{
${ }^{a}$ Departamento de Letras e Programa de Pós-graduação em Letras da Universidade Federal de São Paulo (UNIFESP). E-mail: rafaelminussi@yahoo.com.br.

${ }^{\mathrm{b}}$ Bolsista de Iniciação Científica em Letras na Universidade Federal de São Paulo (UNIFESP). E-mail: carolinesoliveira1995@gmail.com.
} 


\section{Introdução}

Este artigo tem como objeto de investigação os sufixos pejorativos e, como principal questão, entender como o conteúdo pejorativo é expresso por meio deles nas palavras derivadas. Entre os principais sufixos analisados, os quais foram tomados a partir de Sandmann (1989), estão: -ão (cabeção, chorão), -esco (animalesco, carnavalesco), -eiro (pulgueiro, cachaceiro), -ice (burrice, velhice), -ento (ciumento, xexelento), -udo (barrigudo, borrachudo), -agem (malandragem, viadagem), -ada (burrada, putaiada), -aria (bruxaria, putaria). Para a investigação do conteúdo semântico desses sufixos e para a verificação de tal conteúdo pejorativo, foram realizados testes sobre a intuição dos falantes em forma de questionários aplicados. Assim, pudemos verificar, entre outras coisas, se a base já era pejorativa, ou se o sufixo realmente trazia uma contribuição para a interpretação da pejoratividade.

Segundo Frota (1985), esses sufixos, em sua maioria, possuem função não somente gramatical como também semântica. Logo, podemos observar uma possível regularidade entre sufixos e determinados significados (FROTA, 1985). Essa regularidade evidencia que há sistematicidade na produção de formas derivadas sufixalmente, o que pode ajudar na descrição e análise dos processos derivacionais na formação de palavras, tanto nas formações que já existem quanto nas novas.

Entendemos que o pejorativo pode ser definido como termo utilizado para expressar conceitos negativos e/ou desvalorizados por determinado grupo social, incluindo indivíduos, atos e/ou características em desacordo com padrões estéticos e culturais do grupo em questão. Nas palavras de Frota (1985, p. 6 - 7):

O pejorativo é uma marca linguística, característica de expressões que designam algo negativamente valorizado por um grupo social, falante de determinada língua. Caracteriza-se por ser um conceito metalinguístico, ou seja, só é aplicável a palavras ou grupos de palavras (talvez também a entonações), e não ao referente das mesmas.

Se há, de fato, uma parcela de significado em determinados sufixos que pode influenciar nas formas derivadas resultantes, até que ponto este significado pode definir uma formação como pejorativa? Tratamos aqui não apenas do significado 
dos sufixos, mas também do significado das bases e de seus produtos, da carga semântica negativa que cada um suporta individualmente e as relações que estes estabelecem entre si.

Na literatura, a morfologia avaliativa, na qual está inserida a pejoratividade, é definida, principalmente, através de seu valor semântico, que pode expressar afeição, valorização, depreciação; mais especificamente, podemos falar da sufixação avaliativa. Essa tem sido dividida em quatro categorias: a) diminutivos; b) aumentativos; c) valorativos e d) pejorativos (VILLALVA, 1994, p.268).

Villalva (1994, p.261) considera que a função dos sufixos avaliativos é modificar a interpretação semântica da base. Consideramos esse pressuposto, visto que alguns sufixos não alteram a semântica da base por completo, apenas acrescentam, intensificam ou atenuam o significado da base. A autora afirma que nem todos os sufixos que expressam a semântica de aumentativos, diminutivos e depreciativos são sufixos pejorativos. São pejorativos apenas aqueles que não alteram a categoria sintática da base, assim como afirma Scalise (1986) em sua característica (1e), como veremos logo a seguir. No entanto, esta afirmação não se sustenta ${ }^{1}$ (STUMP, 1993).

De acordo com Scalise (1986), a morfologia avaliativa possui características tão peculiares que se constituiria em uma subcategoria independente. Por meio de suas pesquisas com o idioma italiano, o autor justifica essa afirmação ao propor seis características que seriam próprias dos afixos avaliativos, são elas:

(1) a. Mudam a semântica da base; b. Permitem a aplicação consecutiva de mais de uma regra do mesmo tipo, e toda aplicação resulta em uma palavra existente; c. Sempre são externos em respeito a outros sufixos derivacionais e internos com respeito aos morfemas flexivos; d. Permitem,

${ }^{1}$ Villalva (1994) traz alguns exemplos em que há uma mudança de categoria por meio do sufixo e também uma interpretação pejorativa: a) chorar (V) vs. chorão (N) e b) empurrar (V) vs. empurrão (N). embora com extensão limitada, a aplicação repetida da mesma regra nos domínios adjacentes; e. Não mudam a categoria sintática da base a qual estão vinculadas; f. Não mudam características (morfo) sintáticas ou a estrutura de subcategorização da base. 
${ }^{2}$ Os exemplos utilizados aqui por Stump (1993) são classificados por Villalva (1994) c o m o s ufixos pseudoavaliativos, pois são sufixos que alteram o gênero da base. Desse modo, segundo Villalva (1994), não fariam parte, portanto, da sufixação avaliativa, o que poderia levantar questionamentos acerca da argumentação de Stump (1993).

${ }^{3}$ Bobaljik (2006), Fortin (2011) e uma série de teóricos questionam se a Morfologia Avaliativa deve ser considerada derivacional ou flexional, não sendo este, porém, o foco do nosso trabalho.

${ }^{4}$ Alguns autores como Potts (2006) e Fortin (2011) referem-se à Morfologia Avaliativa como "Morfologia E x p r e s i va", como já dissemos, continuaremos a utilizar o termo morfologia avaliativa.
Stump (1993, p.5), porém, afirma que os princípios propostos por Scalise (1986) não generalizam bem as características encontradas nas línguas e as questiona. As regras de morfologia avaliativa podem sim, em alguns momentos, afirma o autor contrariando (1c), ser posteriores, como vemos em Southern Barasano (Base singular: coti "pote", Diminutivo singular: cotiaka, Base plural: cotiri "potes", Diminutivo plural: cotiriaka), nos quais o sufixo diminutivo é alocado após a flexão de plural, ou até mesmo estarem entre as regras flexionais, como vemos nos dados do português: (animalzinho, pl. animai-zinho-s; compare com animai-s). É possível também que as regras avaliativas se apliquem antes das regras de derivação sufixal, por exemplo, em espanhol (Base: bandera "bandeira", Diminutivo: banderilla "bandeira decorada usada em touradas", Derivativo pessoal em -ero: banderillero "aquele que insere a bandeira nas touradas").

Stump (1993) também defende que as propriedades sintáticas (1e) e (1f) são desconstruídas através de exemplos que demonstram a mudança de categoria sintática. Nesse caso, uma mudança de gênero masculino e feminino não somente é possível, e até mesmo comum, como também é a mudança de gênero que torna uma formação pejorativa em alguns casos. Por exemplo, na língua tigre, a afixação de uma marca de gênero oposta à da base, fornece um sentido pejorativo à palavra formada: (i) anas (homem. masc. sing.) "homem"; (ii) anesay (homem. masc. sing. diminutivo) "homenzinho"; (iii) anesät (homem. fem. sing) "forma pejorativa para homem". Com uma base feminina, a inserção de um afixo masculino torna a palavra pejorativa: (i) assit (mulher. fem. singular) "mulher"; (ii) assität (mulher. fem. diminutivo) "mulherzinha"; (iii) assitay (mulher, masc. singular) "forma pejorativa para mulher" 2 .

Por meio de exemplos como os citados, Stump (1993) conclui que as regras avaliativas são muito mais livres do que assume Scalise (1986), ora compartilhando propriedades derivacionais, ora flexionais ${ }^{3}$. Desse modo, não se pode fundamentar efetivamente a existência de um subcomponente exclusivo para a morfologia avaliativa, como assume Scalise (1986).

Há também teóricos que propuseram critérios para melhor definir a semântica do conteúdo avaliativo ${ }^{4}$, no qual se insere o pejorativo. 
Partindo das reflexões levantadas por Scalise (1986), Stump (1993) e Villalva (1994), postulamos algumas questões que nos guiaram neste trabalho: a) quais são os critérios para identificar uma formação como pejorativa?; b) de que modo os sufixos contribuem para a interpretação na formação de palavras pejorativas?; c) os sufixos pejorativos possuem conteúdo semântico em si mesmos?; d) há a necessidade de tratar a morfologia avaliativa como um componente independente, assim como propõe Scalise (1986)?; e, por fim, e) de que modo as formações pejorativas podem contribuir para a questão em d)?

\subsection{A teoria de fase nas palavras e a interpretação pejorativa}

A fim de verificarmos a necessidade de tratar a morfologia avaliativa ou as formações pejorativas em um componente independente, vamos lançar mão da teoria de fase de Marantz (2001) e Arad (2003) e mostrar como seria uma possível análise da pejoratividade em uma teoria não lexicalista. A hipótese que lançamos é que o significado pejorativo das palavras deve ser negociado na primeira fase, ou seja, após a primeira concatenação de um categorizador, que é realizado fonologicamente por sufixos como -ão, -agem, -ento, -eiro, entre outros.

No que diz respeito diretamente à estrutura morfológica das formações pejorativas, podem ocorrer casos em que: a) a base já é pejorativa e se soma a um sufixo também pejorativo (ex.: cafona/cafonice, rabugem/rabugento, malandro/malandragem); b) a base é neutra e se soma a um sufixo pejorativo (ex.: mandar) mandão, política/politiqueiro, meigo/meiguice). Os casos em b) poderiam contrariar a teoria de fase, caso se verifique que, de fato, houve uma categorização anterior à inserção e uma categorização com o chamado sufixo pejorativo. Os testes que serão realizados servirão para verificar se a pejoratividade já é interpretada na base categorizada, ou após a sufixação e categorização por meio de um sufixo chamado pejorativo.

A teoria de fase (MARANTZ, 2001 e ARAD, 2003) foi desenvolvida dentro do modelo da Morfologia Distribuída, (Cf. HALLE e MARANTZ, 1993 e MARANTZ, 1997) uma teoria não 
lexicalista que propõe serem tanto palavras quanto sentenças geradas no mesmo componente: a sintaxe.

A arquitetura da gramática na MD é composta por três listas. A Lista 1 contém os chamados traços morfossintáticos, que são elementos destituídos de conteúdo fonológico, tais como raízes, traços de número, pessoa, categorizadores que podem formar nomes, adjetivos e verbos, por exemplo, entre outros elementos. Esses elementos, que são primitivos, alimentam a derivação sintática. Já na sintaxe podem ser submetidos a operações sintáticas (concatenar, mover) para a formação das palavras e sentenças e, em seguida, são enviados, por meio da operação de spell-out, para PF (do inglês Phonetic Form) e LF (Logical Form).

No caminho para PF, está localizada a Lista 2 (também chamada de Vocabulário), que armazena os Itens de Vocabulário, os quais são regras que unem os traços morfossintáticos a expoentes fonológicos. É neste ponto da arquitetura da gramática que são inseridas as formas fonológicas por meio de uma operação chamada de spell-out fonológico.

Por sua vez, a Lista 3, chamada Enciclopédia, contém o conhecimento extralinguístico e faz interface com o sistema conceitual-intencional. É também na Lista 3 que estão os significados especiais para as raízes. Essa lista possui forte ligação com o contexto de uso das formações; contém os significados especiais das raízes, que são aqueles que não podem ser previstos através da estrutura. Por exemplo, se ouvimos a frase: "Há um gato ali", podemos pensar em três significados: a) "há um mamífero de quatro patas da família dos felinos ali", ou b) "há um sujeito do sexo masculino de excelente aparência ali", ou ainda c) "há um emaranhado de fios fazendo uma ligação ilegal para o fornecimento de algum serviço ali". Esses possíveis significados para "gato" devem estar listados na Enciclopédia e são parte do conhecimento de mundo de um determinado falante.

A arquitetura da gramática pode ser observada na figura a seguir: 
Figura 1 - Arquitetura da Linguagem

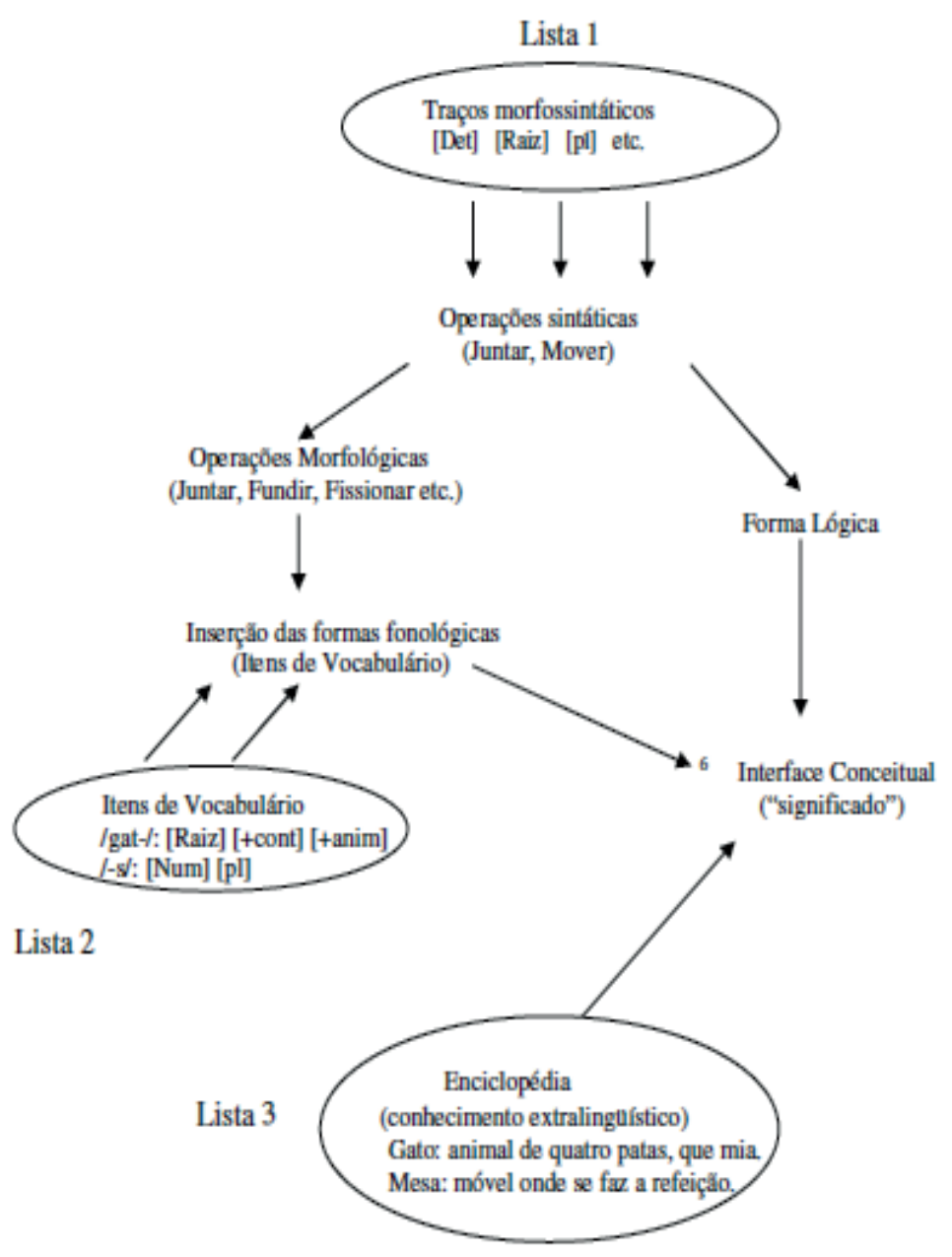

Fonte: MEDEIROS, 2008, p.18

A MD torna-se um modelo interessante para nosso estudo ao utilizar a noção de fase nas palavras. Essa noção nos permite investigar os limites da construção semântica, em que momento ela ocorre e como esse momento da negociação de significado influencia nas formas resultantes. Marantz (2001, p.6) propõe a existência de dois lugares de formação de palavras que emergem da estrutura sintática após as operações na sintaxe. $\mathrm{O}$ autor chama esses lugares de fases, tomando como base a denominação de Chomsky (2001). Como argumento principal, ele afirma que há evidências para a existência de dois domínios em que um morfema pode ser concatenado a: 
um domínio interno (inner), sendo essa a primeira fase, e um domínio externo (outer), a segunda fase. Os domínios interno e externo estão relacionados com a produtividade e o tipo de interação que os afixos estabelecem com a raiz (root). O domínio interno ou, também, primeira fase, está no domínio da raiz e ocorre quando um morfema (um núcleo funcional, na figura 2 , representado por head) é adjungido à raiz. No domínio externo, são construídas as palavras fora do domínio do núcleo funcional categorizador, representado por " $x$ " na figura 2 . Como vemos na figura a seguir:

Figura 2 - domínios interno e externo
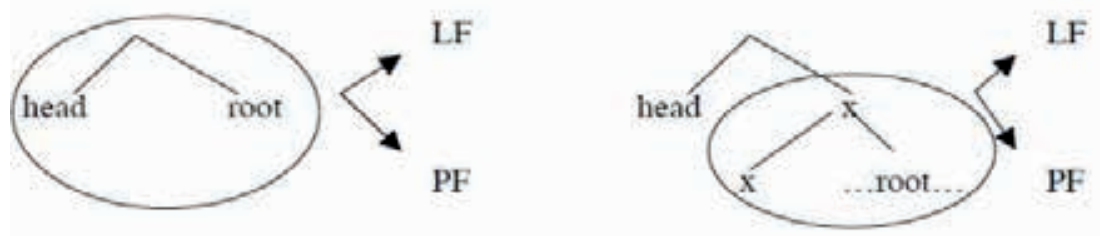

Fonte: MARANTZ, 2001, p. 07

Na derivação e na estrutura, 0 " $x$ " (núcleo categorizador, que pode ser $n, v$ ou a) determina o limite da fase. A combinação entre raiz e " $\mathrm{x}$ " é enviada para PF e LF para interpretação fonológica e semântica, e o significado da raiz no contexto de " $x$ " é negociado, usando o conhecimento enciclopédico do falante.

Arad (2003) amplia a noção de fase delineada em Marantz (2001) e mostra suas aplicações aos dados. A autora apresenta uma hipótese relevante para nossas investigações, a teoria da Restrição de Localidade para Interpretações nas Raízes (Locality Constraints On The Interpretation Of Roots), pois, entre as características próprias da morfologia avaliativa, propostas por Scalise (1986) e já citadas, está a principal propriedade distintiva desse tipo de formação: (1a) a mudança semântica. Nessa hipótese, Arad (2003) investiga os limites das interpretações semânticas e como essas são determinadas pelo contexto que as cerca.

Arad (2003, p. 738-739) propõe os seguintes argumentos: a) raízes podem adquirir diferentes interpretações em diferentes 
ambientes morfofonológicos e, embora essas interpretações retenham e compartilhem de algum núcleo de significado da raiz, elas frequentemente são distantes semanticamente umas das outras, e não há como serem previstas através da combinação de raiz e um núcleo categorizador $(n, v$ ou $a)$; b) a habilidade de promover múltiplas interpretações é exclusiva das raízes. Uma vez que a raiz é concatenada a um núcleo categorizador e é formada uma palavra, sua interpretação é fixada e, então, é carregada ao longo de toda a derivação. Essa restrição de localidade é universal e permeia todas as línguas.

Assim sendo, Arad (2003), juntamente com Marantz (2001), propõe que é na primeira categorização de uma raiz, o domínio interno para Marantz (2001), que temos a negociação do significado da palavra. Essa semântica formada na primeira categorização da raiz permanece nas categorizações subsequentes.

Partindo desses pressupostos, é estabelecida uma distinção entre palavras formadas a partir de raízes (e.g. destruir: $\sqrt{ } D E S T R U+i$ r) e palavras formadas através de outras palavras (e.g. apertamento: apertado + apartamento). Quando a palavra é formada a partir de uma raiz, o primeiro núcleo nominal, adjetival ou verbal ao qual a raiz se concatena serve como condição imediata que determina sua interpretação. Por sua vez, as palavras formadas por meio de outras palavras suportam um conjunto de características semânticas e fonológicas que resultam da primeira concatenação.

É na primeira fase, portanto, que palavras criadas diretamente de raízes têm seu significado específico negociado por meio do conhecimento pragmático e extralinguístico presente na Enciclopédia (Lista 3). Tomemos como exemplo as seguintes formações: a) corredor: "aquele que corre" e b) corredor: "passagem longa e estreita" (Cf. PEDERNEIRA, 2010). Além do significado, o que distingue essas duas formações?

No exemplo a), temos a raiz $\sqrt{ } C O R R$ que é verbalizada dando origem a correr que, em seguida, é nominalizada através do sufixo agentivo -dor. Seu significado foi negociado na primeira concatenação, quando a raiz foi concatenada a um categorizador verbal e se tornou o verbo correr "se deslocar com velocidade". Após, durante a segunda concatenação, quando é acrescido o morfema agentivo -dor, a forma resultante mantém um núcleo de significação já negociado na fase anterior, no 
caso o significado do verbo correr, que continua a estabelecer relações semânticas com a forma seguinte, logo, corredor é "aquele que corre".

Em contrapartida, como propõe Pederneira (2010), em b) corredor "passagem longa e estreita", a raiz $\sqrt{ } C O R R$ é nominalizada diretamente pelo sufixo categorizador -dor, e podemos observar que seu significado é definido neste primeiro momento, ou seja, na primeira concatenação, sem uma fase verbal. Isto é, não há verbalização, há somente a vogal temática " $\mathrm{e}$ " que surge para atender necessidades morfofonológicas de boa formação. ${ }^{5}$ Podemos concluir, por meio desta breve análise, que o que diferencia as formações a) e b) não é apenas o significado, mas também em que momento esse significado foi negociado e estabelecido; e como formações originadas na segunda fase, como em a), mantêm uma o significado negociado nas categorizações anteriores.

Seguindo a teoria de fase de Marantz (2001) e Arad (2003), a hipótese que lançamos é que o significado pejorativo das palavras deve ser negociado na primeira fase, ou seja, após a primeira concatenação de um categorizador, que é realizado fonologicamente por sufixos, como: -ão, -agem, -ento, -eiro, entre outros.

Assim sendo, colocamos as seguintes questões para a teoria: a) o significado pejorativo é dado na primeira concatenação de um sufixo às raízes? b) Há sufixos pejorativos que podem ser alocados após a primeira categorização? Quais seriam, então, os sufixos pejorativos que se concatenam diretamente na primeira fase e quais seriam incluídos após a primeira concatenação de um categorizador? Como consequência das respostas encontradas, ainda teríamos as seguintes perguntas: i) caso os sufixos se concatenassem à

${ }^{5}$ Ao analisar o expoente /nt/, Medeiros (2006) a presenta $\mathrm{um} \mathrm{a}$ composição semântica semelhante ao exemplo citado ("corredor") para a formação "corrente". Bassani (2009) também aborda os possíveis estágios da estrutura semântica, utilizando verbos não denominais apresentando diversos testes. raiz, poderiam eles criar significado? Isto é, estando inseridos na primeira fase, os sufixos pejorativos poderiam determinar interpretações?; (ii) no caso de os sufixos se anexarem a palavras já existentes, as palavras formadas carregariam algum significado já negociado, ou os sufixos, ainda assim, poderiam modificar seu significado por completo? Por meio dessas hipóteses, visamos investigar os ambientes sintáticos que influenciam as formações pejorativas derivadas sufixalmente e a natureza dessas formações. 


\section{Formação do banco de dados e metodologia}

Os dados selecionados foram coletados em diversas mídias com o objetivo de permear os mais diversos contextos. Entrevistas, diálogos reais, letras de músicas, textos escritos, cenas de novela e pesquisas em dicionários on-line no Google, tais como: Houaiss, Aulete, Priberam, entre outros. Cada palavra que foi classificada como pejorativa, por meio de nossa intuição, foi coletada, uma vez que, segundo o modelo teórico adotado, a MD, a intuição do falante é fundamental, e podemos, inicialmente, nos guiar por ela.

Os sufixos que integram os dados, respectivamente, são: -ão, -esco, -eiro, -filo, -oide, -ice, -ento, -udo, -agem, -ada, -aria, -oso, -eco e -ista. No total, são 18 palavras com o sufixo -ão; 8 palavras com o sufixo -esco; 57 palavras com o sufixo -eiro; 2 palavras com o sufixo -filo; 6 palavras com o sufixo -oide; 31 palavras com o sufixo -ice; 49 palavras com o sufixo -ento; 47 palavras com o sufixo -udo; 22 palavras com o sufixo -agem; 23 palavras com o sufixo -ada; 08 palavras com o sufixo -aria; 22 palavras com o sufixo -oso; 3 palavras com o sufixo -eco e 10 palavras com o sufixo -ista, somando 306 palavras. Entre as palavras coletadas estão: encheção, enrolão, animalesco, caricaturesco, poeteiro, politiqueiro, cinéfilo, pedófilo, comunistoide, debiloide, babaquice, baianice, piolhento, pirracento, borrachudo, bocudo, libertinagem, malandragem, sarrada, trepada, bruxaria, gritaria, jeitoso, manhoso, traveco, xaveco, comunista, satanista, etc.

\section{A intuição sobre pejoratividade: aplicando os questionários}

A fim de testar as hipóteses lançadas e não apenas utilizar nossa própria intuição sobre pejoratividade, foram realizados dois pré-testes e um teste final baseado nos resultados dos pré-testes realizados anteriormente. Devido à quantidade de palavras (306), nem todas as palavras foram incluídas. A organização das formações foi aleatória e, além das questões sobre os dados, coletamos informações sobre a escolaridade, faixa etária e gênero dos participantes. Estabelecemos que o número mínimo de participantes seria de 50 e todos os testes ficaram disponíveis durante um período de cinco dias. Os testes foram divulgados através de redes sociais pessoais e de 
comunidades virtuais relacionadas com a Universidade Federal de São Paulo, além de grupos relacionados com universitários e acadêmicos, por isso, a maioria dos participantes se encontra na faixa entre 18 e 29 anos e cursando o Ensino Superior.

Foi utilizado o formulário do Google para a realização da pesquisa com o seguinte texto: “O pré-teste que se segue tem como objetivo compreender a pejoratividade de determinadas palavras para que melhor possamos classificá-las, qualificá-las e descrevê-las em nossa pesquisa. Entendemos que o pejorativo pode ser definido como termo utilizado para expressar conceitos negativos e/ou desvalorizados por determinado grupo social, incluindo indivíduos, atos e/ou características em desacordo com padrões estéticos e culturais do grupo em questão. "Diz-se da palavra empregada em sentido torpe, obsceno ou simplesmente desagradável; depreciativo" (MICHAELIS, 2008)". Em seguida, solicitamos que o participante assinalasse todas as palavras que possuíssem um sentido pejorativo.

\subsection{Resultados dos questionários}

\section{Pré-teste 1}

O pré-teste 1 foi elaborado com as palavras consideradas base das formações contidas no corpus. ${ }^{6}$ Esse pré-teste foi necessário para estabelecer se as bases das palavras derivadas podiam ser consideradas como pejorativas, ou não. Assim, poderíamos analisar se a interpretação pejorativa surgia com a concatenação do sufixo, ou seja, se ela já existia. Teoricamente, estávamos testando se a interpretação pejorativa já existia no domínio interno, primeiro categorizador, ou se ela surgia em um domínio externo, depois da primeira concatenação.

Tal pré-teste foi respondido por 210 pessoas. Considerando que o pré-teste em questão foi composto por bases, optamos por analisar as vinte opções mais assinaladas

${ }^{6}$ Agradecemos ao Prof. Dr. José Ferrari Neto (UFPB) por nos ajudar na elaboração dos questionários e entender a pertinência dos pré-testes, além de toda a paciência para responder nossas dúvidas a respeito de criação de questionários e experimentos off-line. pelos respondentes. Entre as 137 formações analisadas, as opções mais assinaladas foram:

1. puta $(82,9 \%), 2$. bicha $(74,8 \%), 3$. viado $(74,8 \%), 4$. rabo $(65,7 \%), 5$. cabaço $(65,7 \%), 6$. teta $(62,9 \%)$, 7. chifre $(58,1 \%), 8$. trepar $(58,1 \%), 9$. rapariga $(58,1 \%), 10$. cagar $(56,7 \%), 11$. sarrar $(49,5 \%), 12$. fuleiro $(45,7 \%), 13$. cafajeste $(44,3 \%), 14$. burro $(39,5 \%)$, 15. chilique $(39,5 \%), 16$. gordo $(35,7 \%)$, 17. moleque $(33,3 \%), 18$. crente $(30,5 \%), 19$. feio $(25,7 \%), 20$. vacilar $(25,7 \%)$. 


\section{Pré-teste 2}

O pré-teste 2 contemplou as formações derivadas do corpus e, em razão de sua extensão, foi dividido em duas partes. Tanto na parte A quanto na parte B, optamos por analisar as formações pejorativas que obtiveram um índice igual ou superior a $50 \%$ de respostas.

\section{Resultados do Pré-teste 2 (parte A)}

A parte A do pré-teste 2 foi respondida por 171 pessoas. Foram analisadas 127 formações; entre as palavras que atingiram um índice maior que 50 por cento estavam:

1. cagão $(82,5 \%), 2$. filha da putice $(72,5 \%), 3$. baianice $(71,9 \%), 4$. filha da putagem $(67,8 \%), 5$. cabeção $(66,7 \%), 6$. fedorento $(66,1 \%)$, 7. chorão $(65,5 \%), 8$. barraqueiro $(65,5 \%), 9$. cachaceiro $(65,5 \%), 10$. catarrento $(65,5 \%)$, 11. enrolão $(64,9 \%), 12$. chifrudo $(64,9 \%)$, 13 . infantiloide $(63,7 \%), 14$. fofoqueiro $(62,6 \%)$, 15. bucetudo $(60,8 \%), 16$. cabacice $(59,6 \%), 17$. burrice $(57,9 \%), 18$. cafonice (57,9\%), 19. carniceiro (56,7\%), 20. breguice (56,1\%), 21. desgracento $(55,6 \%), 22$. babaquice $(54,4 \%)$, 23. barrigão $(53,8 \%)$, 24 . chiliquento $(53,2 \%), 25$. crentice $(52,6 \%), 26$. beiçudo $(52,6 \%)$, 27. asqueroso $(51,5 \%)$.

Assim sendo, entre os sufixos presentes nas 27 palavras que obtiveram um índice acima de $50 \%$, na parte A do segundo pré-teste estavam: 8 palavras com o sufixo -ice; 5 palavras com o sufixo -ão; 4 palavras com o sufixo -ento; 4 palavras com o sufixo -eiro; 3 palavras com o sufixo -udo; 1 palavra com o sufixo -oide; 1 palavra com o sufixo -agem e 1 palavra com o sufixo -oso.

\section{Resultados do Pré-teste 2 (parte B)}

A parte B do pré-teste 2 foi respondida por 59 pessoas. Entre as 133 palavras analisadas, as que atingiram um índice maior que 50 por cento foram: 1 . punheteiro $(81,4 \%)$, 2 . sapatão $(74,6 \%)$, 3. vacilão $(72,9 \%), 4$. remelento $(72,9 \%), 5$. mulambento $(71,2 \%), 6$. piolhento $(71,2 \%), 7$. viadice $(69,5 \%), 8$. xexelento $(69,5 \%), 9$. debiloide $(69,5 \%), 10$. puteiro $(67,8 \%), 11$. negrice $(67,8 \%), 12$. pidão $(66,1 \%), 13$. putice $(66,1 \%), 14$. perebento $(66,1 \%)$, 15. porquice $(64,4 \%), 16$. putaiada $(64,4 \%), 17$. reclamão $(62,7 \%)$, 18. respondão $(62,7 \%)$, 19. pulguento $(59,3 \%)$, 20. viadagem $(59,3 \%), 21$. pirracento $(57,6 \%), 22$. ranhento $(57,6 \%), 23$. mandão $(55,9 \%), 24$. gastão $(55,9 \%), 25$. muambeiro $(55,9 \%), 26$. nojentice 
(55,9\%), 27. lazarento (52,5\%), 28. verruguento (52,5\%), 29. seboso $(52,5 \%)$, 30. trapaceiro $(50,8 \%), 31$. peçonhento $(50,8 \%), 32$. rabugento $(50,8 \%)$, 33. pançudo $(50,8 \%)$, 34 . vadiagem $(50,8 \%)$, 35. putaria $(50,8 \%)$.

Entre os sufixos encontrados nas 35 palavras que obtiveram um índice acima de $50 \%$, na parte B do segundo pré-teste, estavam: 12 palavras com o sufixo -ento; 7 palavras com o sufixo -ão; 5 palavras com o sufixo -ice; 4 palavras com o sufixo -eiro; 2 palavras com o sufixo -agem; 1 palavra com o sufixo -udo; 1 palavra com o sufixo -oide; 1 palavra com o sufixo -oso; 1 palavra com o sufixo -aria e 1 palavra com o sufixo -ada.

\subsection{Analisando os pré-testes}

A base mais assinalada no pré-teste 1 foi puta $82,9 \%$, considerada a base mais pejorativa, e apareceu no pré-teste $2 \mathrm{com}$ as formações filha da putice $72,5 \%$, filha da putagem $67,8 \%$, puteiro $67,8 \%$, putice $66,1 \%$, putaiada $64,4 \%$ e putaria com $50,8 \%$. Desse modo, além de ser a base mais pejorativa, todas as formações a ela associadas obtiveram altos índices de pejoratividade.

No pré-teste 1, a base infantil obteve um índice de $14,3 \%$, enquanto a formação infantiloide obteve $63,7 \%$ das respostas. As intuições encontradas para infantiloide contrariam, portanto, a noção de fase (Cf. MARANTZ, 2001, ARAD, 2003) (abordada na seção 1.1), pois a base, aqui representada pela raiz $\sqrt{\text { INFANT }}$ + a (infantil), pode ser considerada neutra e o sufixo -oide, que é a realização de um categorizador $a$, pode ser considerado o responsável pela interpretação pejorativa, que, neste caso, parece ter sido estabelecida na segunda fase.

(2)

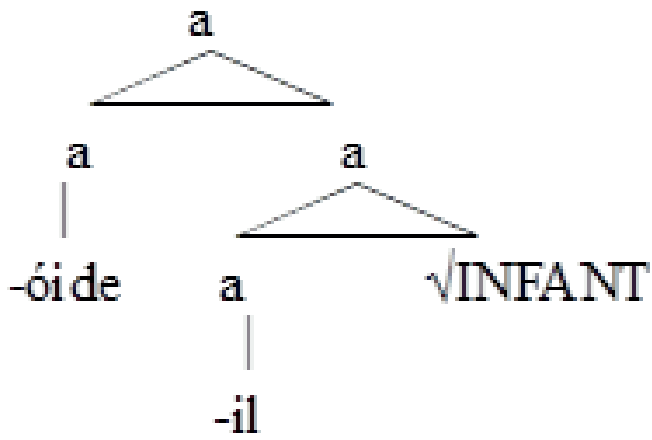


Contudo, a formação debiloide, cuja base débil é indicada em dicionários como pejorativa, obteve um índice de $69,5 \%$; isto significa que a palavra derivada parece manter a pejoratividade da base que foi previamente estabelecida na primeira categorização. Portanto, não temos evidências suficientes para chegarmos a conclusões sobre o sufixo -oide e deixamos aqui a sugestão para novas investigações.

Não obtivemos formações com o sufixo -esco, com índices acima de $50 \%$ no pré-teste 2 . Poderíamos pensar que esse resultado se deve à pouca quantidade de formações com esse sufixo no banco de dados, apenas oito palavras. No entanto, as formações com o sufixo -oide, que possuem ainda menos formações (apenas seis), no nosso banco de dados, tiveram duas ocorrências com índices acima de 50\%, de modo que concluímos que -esco não parecer ser, de fato, um sufixo pejorativo.

O sufixo -oso obteve duas formações com índices acima de $50 \%$ no pré-teste 2 . Os resultados foram pouco expressivos, considerando a quantidade de formações com esse sufixo presente no bando de dados, um total de 22 formações. Porém, devemos perceber que para ambas as formações, asqueroso $51,5 \%$ (parte A) e seboso $52,5 \%$ (parte B), suas bases correspondentes (pré-teste 1) obtiveram baixos índices de escolha, asco $16,7 \%$ e sebo $21 \%$.

O sufixo -ada apresentou um resultado relevante nos prétestes, as bases correspondentes obtiveram um índice maior do que as formações resultantes, como, por exemplo, trepar $58,1 \%$ e trepada $39 \%$, sarrar $49,5 \%$ e sarrada 30,5\%, burro 39,5\% e burrada $28,1 \%$, algo não previsto. Para comprovarmos ou refutarmos esse resultado, acrescentamos dados similares no teste final.

Os sufixos -ão, -udo e -agem não apresentaram evidências que suscitassem alguma consideração, conclusão e/ou hipótese.

Como resultado geral do pré-teste 2 , entre as 62 formações que atingiram índices acima de $50 \%$, obtivemos a seguinte ordem: -ento com 16 formações (25,8\%); -ice com 13 formações (20,96\%); -ão com 12 formações (19,35\%); -eiro com 8 formações (12,9\%); -udo com 4 formações (06,45\%); 3 formações com o sufixo -agem (04,83\%); -oso e -oide, ambos com 2 formações (3,22\% cada um) e, por fim, -ada e -ária, ambos com apenas 1 formação (1,61\% cada um). Foi com base nesses resultados que formulamos o teste final. 


\subsection{O questionário final e análise dos dados}

Um questionário final foi elaborado com base nos resultados dos pré-testes aplicados, a fim de que pudéssemos confirmar e/ou refutar hipóteses concebidas a partir dos respectivos resultados.

Assim sendo, o questionário para o teste final foi respondido por 263 pessoas. Nesse questionário, foram apresentados 17 pares de palavras, e os participantes selecionavam, entre os pares de palavras, a palavra mais pejorativa de cada par.

Encontramos os seguintes resultados para os pares:

01 . burrice $79,8 \%$ - burrada 20,2\%, 02. viadagem 79,1\% viadice $20,9 \%, 03$. pulguento $76,8 \%$ - pulgueiro $23,2 \%$, 04 . teta $19,4 \%$ - tetudo $80,6 \%$, 05 . trepar $27,8 \%$ - trepada $72,2 \%$, 06 . rabo $27 \%$ - rabudo $73 \%$, 07. puteiro $64,3 \%$ - putice $35,7 \%, 08$. putaiada $\underline{80,2 \%}$ - puteiro 19,8\%, 09. putaria $65,4 \%$ - puteiro $34,6 \%, 10$. putice $24,3 \%$ - putaiada $75,7 \%$, 11 . putice $31,2 \%$ - putaria $68,8 \%$, 12. putaiada $58,9 \%$ - putaria $41,1 \%, 13$. filha da putice $42,6 \%$ - filha da putagem $57,4 \%$, 14 . sarrar $25,9 \%$ - sarrada $74,1 \%$, 15. carniceiro $31,6 \%$ - carnicento $68,4 \%$, 16. gorduroso $18,6 \%$ gordurento $81,4 \%$, 17 . cachaceiro $35 \%$ - piolhento $65 \%$

Entre os 17 pares de palavras propostos no questionário final, encontramos os seguintes sufixos com um índice superior a 50\%: 5 palavras com o sufixo -ada; 4 palavras com o sufixo -ento; 2 palavras com o sufixo -agem; 2 palavras com o sufixo udo; 2 palavras com o sufixo -aria e 1 palavra com o sufixo -ice.

No par 2, no qual foi solicitado ao participante que optasse pela formação mais pejorativa entre a dupla viadagem $\mathrm{e}$ viadice, viadagem obteve o maior índice, $79,1 \%$. Em uma pesquisa no site Google, observamos que a palavra viadagem é citada 370.000 vezes, enquanto viadice é citada apenas 39.400 vezes. Considerando que todos os outros resultados demonstram que o sufixo -ice é mais pejorativo do que o sufixo -agem, hipotetizamos que viadagem foi selecionada mais vezes em razão da frequência de uso. Isto é, viadagem é um termo mais utilizado pelo falante, aparece com mais frequência, e isso reforça sua pejoratividade em relação à formação viadice.

Os pares 3 (pulguento/pulgueiro), 15 (carniceiro/carnicento) e 17 (cachaceiro/piolhento) apresentam dados que comparam o sufixo -eiro ao sufixo -ento. Segundo os resultados anteriores, 
7 A Força d e Pejoratividade se refere à capacidade de o sufixo de ressaltar o u provocar a interpretação pejorativa de uma formação derivada, considerando o ambiente e as condições providas por suas bases. Assim, uma vez que encontramos mais palavras que foram interpretadas pejorativamente com o sufixo - ento, estamos considerando que tal sufixo possua uma maior "força de pejoratividade". Novas considerações podem ser feitas a esse respeito. Por motivos de espaço, reduzimos essa discussão que pode ser encontrada na íntegra, assim como uma discussão sobre critérios de pejoratividade, no Relatório Final de Iniciação Científica (OLIVEIRA, C.S.; 2017) submetido à FAPESP, processo n ${ }^{\circ} 2015 / 24906$ 4. -ento seria o sufixo mais pejorativo presente no corpus, o que também pode ser confirmado pelos resultados dos pares 3 e 17. Por sua vez, o par 15, no entanto - apesar de -ento novamente obter o maior índice com carnicento, a outra formação presente na dupla, carniceiro - é a formação mais frequente no site de busca Google (404.000 citações para carniceiro e 5.580 citações para carnicento). Como mencionamos anteriormente, lançamos a hipótese de que a formação mais frequente deve possuir uma maior força de pejoratividade. Nesse caso, porém, isso não ocorre, o que corrobora com os resultados da pesquisa que afirmam que -ento é o sufixo mais pejorativo. Sua força de pejoratividade ${ }^{7}$ é tão grande que é capaz de se sobrepor a uma formação mais frequente.

No par 3, a formação pulguento (76,8\%) obteve maior índice do que pulgueiro (23,2\%). Como podemos observar a seguir, em (3) e (4), estamos analisando que ambas as formações, pulguento e pulgueiro, são formadas na primeira fase, ou seja, os sufixos -ento e -eiro se concatenam diretamente à raiz e, assim, têm suas interpretações negociadas na primeira concatenação do categorizador $a$ e $n$, respectivamente. Tal análise se apoia na morfologia das palavras, uma vez que em pulguento e pulgueiro não encontramos o índice temático -a presente em pulga . Podemos ressaltar ainda que pulga, analisada como base no pré-teste 1 , obteve um índice de apenas $06,2 \%$ de escolha para pejoratividade.

(3)

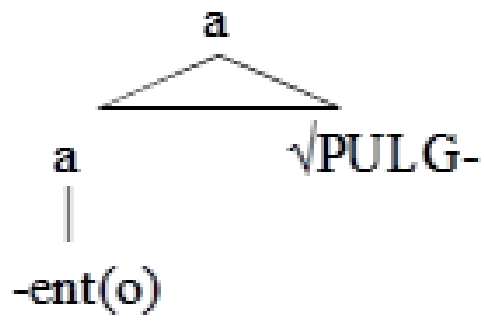

(4)

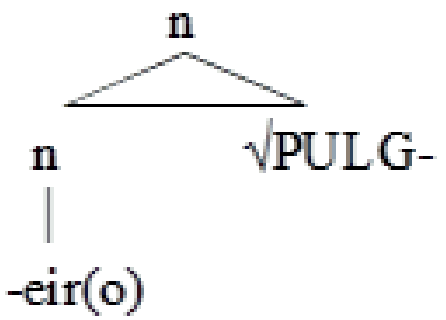


Há uma tendência do sufixo -ento em promover a formação de adjetivos, enquanto -eiro possui uma tendência em promover a formação de nomes. Isso pode indicar, preliminarmente, que a interpretação pejorativa é mais frequente em formações adjetivais, hipotetizando uma relação entre pejoratividade e classe de palavras. No entanto, não obtivemos evidências suficientes para sustentar essa hipótese.

Nos pares 01,05 e 14, podemos observar que as formações com o sufixo -ada apresentam os menores índices, tanto na comparação com outro sufixo (burrice 79,8\% - burrada 20,2\%) quanto na comparação com as bases presentes no teste final (trepar 27,8\% - trepada 72,2\%, sarrar 25,9\% - sarrada 74,1\%). Isso acontece, por hipótese, porque o sufixo -ada mantém a pejoratividade que já foi estabelecida na primeira fase das formações e só é anexado a bases que já são pejorativas, logo, esse sufixo possui pouca força de pejoratividade.

A seguir, podemos observar a formação de sarrada, que contém um verbalizado $v$, realizado pela vogal temática -a. $\mathrm{O}$ verbo sarrar, assim como o verbo trepar, foram avaliados nos pré-testes com altas porcentagens de pejoratividade, $49,5 \%$ e $58,1 \%$ respectivamente.

(5)

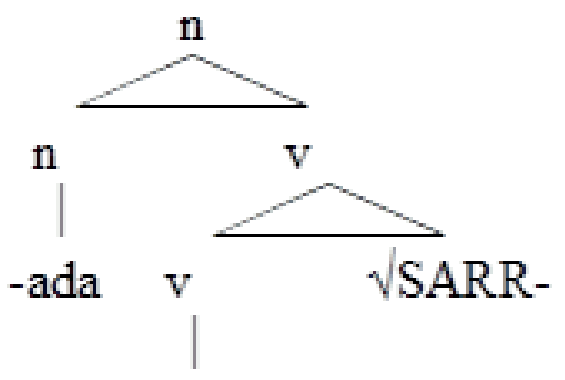

$-\mathrm{a}$

Ainda sobre o par 1, podemos observar também, que o sufixo -ice é a forma mais frequente, além de ser mais forte pejorativamente em relação ao sufixo -ada.

\section{Conclusão}

A fim de tentarmos dar conta de quais critérios são necessários para identificar as formações pejorativas, o presente 
trabalho utilizou-se da aplicação de questionários, nos quais os participantes utilizaram sua intuição para selecionar as formações pejorativas tanto das bases quanto as formações derivadas. O resultado desses questionários, por sua vez, nos ajudou a analisar a contribuição de alguns sufixos para a interpretação pejorativa de uma palavra.

Ao utilizarmos uma teoria como a MD e a noção de fase nas palavras, pudemos observar que, mesmo em uma teoria não lexicalista, podemos analisar a pejoratividade sem a necessidade de um componente específico para tratar da morfologia avaliativa, em especial, a formação das palavras pejorativas, contrariando Scalise (1986).

Oúltimo teste, em particular, contribuiu para observarmos o comportamento dos sufixos quando comparados entre si. Ao tomarmos, por exemplo, uma base como puta, que no pré-teste 1 teve um índice de $82,9 \%$ na escolha dos participantes, e as palavras derivadas a partir dessa base, como: filha da putice $72,5 \%$, filha da putagem $67,8 \%$, puteiro $67,8 \%$, putice $66,1 \%$, putaiada $^{8} 64,4 \%$, putaria $50,8 \%$, todas com índices acima de $50 \%$, pudemos tentar estabelecer uma escala para saber qual era o sufixo mais pejorativo entre eles.

Os resultados da comparação entre os pares, tomando apenas as palavras derivadas da base puta, trouxeram os seguintes resultados: putaiada $80,2 \%$ - puteiro $19,8 \%$; putaria 65,4\% - puteiro $34,6 \%$; puteiro $64,3 \%$ - putice $35,7 \%$; putice $24,3 \%$ - putaiada $75,7 \%$; putice $31,2 \%$ - putaria $68,8 \%$; putaiada $\underline{58,9 \%}$ - putaria 41,$1 ;$ filha da putice $42,6 \%$ - filha da putagem 57,4\%. Assim, baseados nesses dados com a base $p u t a$, podemos sugerir uma escala que vai da forma menos pejorativa para a mais pejorativa, como representado em (6):

(6) putice $<$ puteiro $<$ putaria $<$ putaiada

${ }^{8}$ Devemos ressaltar que a palavra putaiada deve ser analisada como uma variação de putalhada, de modo que o sufixo presente nesta formação não é o sufixo -ada, mas um sufixo -aiada variante de -alhada. Assim, não podemos confundir com o sufixo -ada, presente em martelada, papelada, olhada, etc.

\section{REFERENCIAS}

ARAD, M. Locality constraints on the interpretation of roots: the case of hebrew denominal verbs. Natural language $\mathcal{E}$ linguistic theory 21, p. 737-738. 2003.

BASSANI, I. Formação e interpretação dos verbos denominais do português do Brasil. Dissertação de mestrado, Universidade de São Paulo, 2009. 
BOBALJK, J. D. Itelmen reduplication: Edge-in association and lexical stratification. J Linguistics 42. Cambridge University Press, p.1-22, 2006.

CHOMSKY, N. Derivation by Phase. In: KENSTOWICZ, Michael J. Ken Hale: a life in language. Cambridge: MIT Press, 2001. p. 1-52.

FORTIN, A. The morphology and semantics of expressive affixes.2011. 2013f. Tese (Doutorado em Philosophy in Linguistics). Lady Margaret Hall. University of Oxford. 2011. Disponível em < https://ora.ox.ac.uk/objects/uuid:88a23d7c-c229-49af-9fc92cb35fce9d54 >. Acessado em: 06 mai. 2018.

FROTA, M. P. A expressão do pejorativo em construções morfológicas. 1985. Dissertação (Mestrado em Letras). Departamento de Letras. Pontifícia Universidade Católica do Rio de Janeiro. Rio de Janeiro, 1985.

HALLE, M.; MARANTZ, A. Distributed morphology and pieces of inflection. In: HALE, K.; KEYSER, S. J. (ed.). The view from the Building 20: Essays in honor of Sylvain Bromberger. Cambridge/Massachusetts: MIT Press, 1993.

MARANTZ, A. No Escape from Syntax: Don't Try Morphological Analysis in the Privacy of Your Own Lexicon. In.: DIMITRIADIS, A. et al. (eds). Proceedings of the 21st penn linguistics colloquium. Working Papers in Linguistics. Philadelphia, 1997. P.201-225.

MARANTZ, A . Words and things. Manuscrito, MIT e NYU, 2001.

MEDEIROS, A. B. O particípio presente no português. Revista letras, Curitiba, n. 69, p. 191-211, maio/ago. 2006.

MEDEIROS, A. B. Traços morfossintáticos e subespecificação morfológica na gramática do português: um estudo das formas participiais. Tese de doutorado. UFRJ. Rio de Janeiro, 2008.

MICHAELIS Dicionário Prático - Língua Portuguesa - Nova Ortografia. Pejorativo. Org. Melhoramentos, 2008. 
MINUSSI, R. D; NÓBREGA, V. A. A interface sintaxepragmática na formação de palavras: avaliando pontos de acesso da Enciclopédia na arquitetura gramática. Veredas: Sintaxe das Línguas Brasileiras. Volume 18/1, 2014, p.161-180.

OLIVEIRA, C.S. O pejorativo sufixal: relações entre semântica e sintaxe. Relatório de iniciação científica. Universidade Federal de São Paulo, Guarulhos, 2017.

PEDERNEIRA, I. L. Etimologia e reanálise de palavras. Tese de mestrado. Rio de Janeiro, UFRJ, 2010.

POTTS, C. The expressive dimension. Theoretical Linguistics 33, p.1-27. 2006.

SANDMANN, A. J. A expressão da pejoratividade. Curitiba, 1989.

SCALISE, S. Generative morphology. Dordrecht: Foris. 1986.

STUMP, G. How peculiar is evaluative morphology? Linguistics Faculty Publications. University of Kentucky, 1993. Paper 28.

VILLALVA, A. Estruturas morfológicas: unidades e hierarquias nas palavras do português. Lisboa, 1994. 


\section{Abstract \\ Remarks on the pejorative suffix: testing the speaker's intuition towards a phase theory in words}

We seek to investigate the relationship between the semantic and syntactic factors by focusing on the formation of derivational names by suffix derivation, reflecting on bases, affixes, products, and the relationships established between them. Following the theoretical model of Distributed Morphology (Cf. HALLE; MARANTZ, 1993; MARANTZ, 1997), we propose an investigation and description of the syntactic-semantic interface (Cf. MINUSSI; NÓBREGA, 2014) in which the pejorative formations can be inserted. Based on Frota (1985) and Sandmann (1989), we initially determined which suffixes were to be studied and also based on the phase theory in words (MARANTZ, 2001; ARAD, 2003) we selected our data. That consists of 306 words, through oral and written texts, collected in the most diverse media and having as fundamental concept the speaker's intuition. We perform tests to verify the pejorativeness of the bases, resulting formations and suffixes. The analysis of the respective data resulted in the creation of a pejorativity's scale. Thus, among the objectives achieved in the work are: a) contribute to a research methodology regarding pejorativity, b) investigate the semantic contribution of the suffix to the interpretation of pejorativity, c) progress in the development of studies on pejoratives word formation and d) perform an analysis of pejorativity in the light of phase theory.

Keywords: Pejoratives; Suffixal Derivation; Evaluation Suffixes; Distributed Morphology; Phase Theory. 